\title{
علاقة نوعية الإصابة بخصائص الأداءعلى جهاز عش الغراب برياضة الجمباز
}

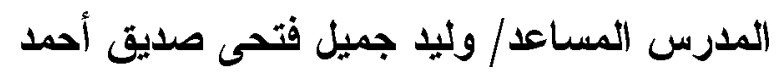

المقدمة:

رياضة الجمباز واحدة من أهم الرياضات الأساسبة التى تلقى حباً وشغفاً لمشاهدتها أو ممارسة الأبناء من الصغر لها، حيث يظهر فيها التتاسق والتاغم وروعة الأداء لقدرات بدنية ومهارية عالية تمنح التميز والإبداع. (1) (11)

إن رياضة الجمباز ثتميز بالصعوبة المهارية للجمل الحركية والثى ثتتوع صعوبثها فتلقى جاذبية وحباً

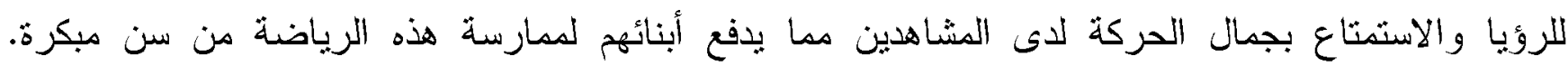

$(1 \cdot: I Y)$

و لا نخلو الرياضات المختلفة من الإصابات والأضرار كالملخ والخلع والثمزقات و الكسور و الكدمات

و الجزوح و غير ذلك من إصابات مختلفة، والتى قد تنتج عن أسباب منعددة مثل الاحتكالك البذنى فى النشاطات النتافسية أو عن أخطاء فى عمليات إعداد الخطط التخريبية وعدم الالنزام الصحيح بمبادئ وأسس التدريب الرياضى أو عدم الكفاية فى الإجراءات الطيية الضرورية لحماية الرياضيين ونوفير العلاجات و الوسائل الوقاية

$(r \cdot r) \cdot r \cdot 4$

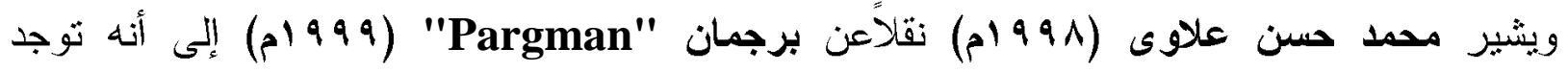
إحصائيات رياضبة نتير إلى أن هناك (V) لاعبين من بين كل (• ( ) لاعبين بعانون الإصابات البدنية الرياضية

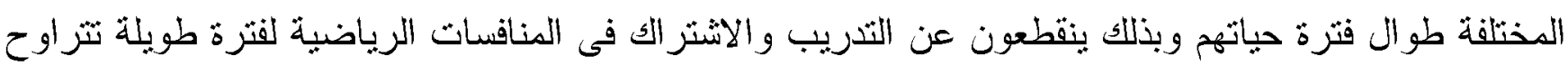
ما بين ثلاث أساييع إلى ثناث شهور · (V)

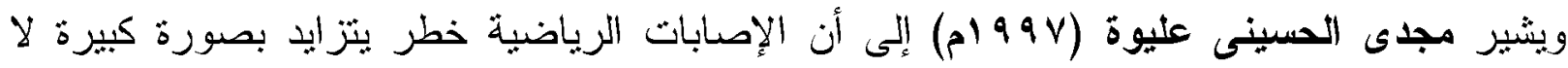
تقتصر فقط على متحدى المسنويات العالبة فى الرياضة والذين يندربون لتسجيل أرقام جديدة وقياسية أو الأداء

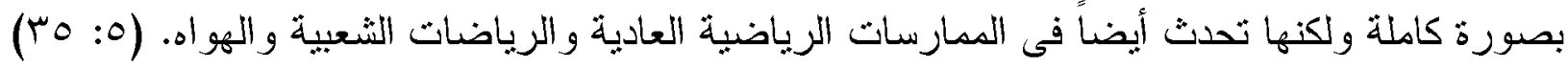

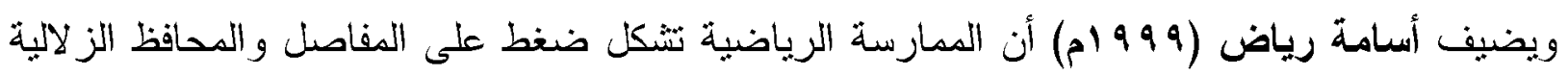
والعضلات والأربطة والأوتار مدا قد بتسبب فى حدوث الإصابات المزمنة، وتتثير الإحصاءات إلى أن إصابات

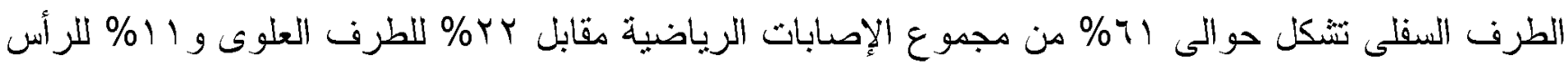
ب\%

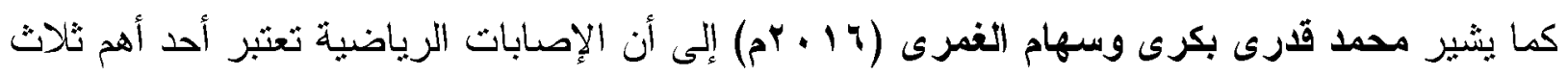

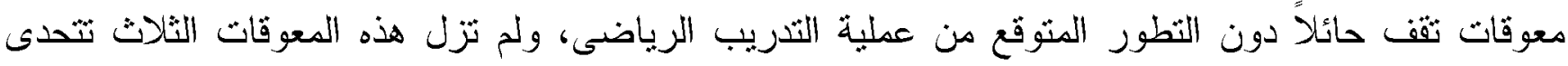

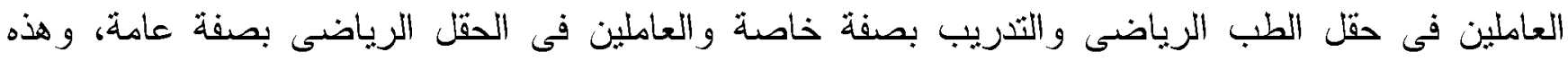
المعوقات هى: التعب، وثقنين الأحمال البدنبة، والإصـابات الرياضية، ولذلك بينوجب الأمر لممارسى الأعمال 
المتعلقة بالرياضة البدنية سواء لاعبين أو ددربين أو إداريين أو العاملين فى حقل التأهيل أن بلموا بكل ما هو جديد فى مجال التعرف على طبيعة هذه الإصابات وإرثباطها بالأنشطة الرياضية المختلفة وطبيعثها وكيفية

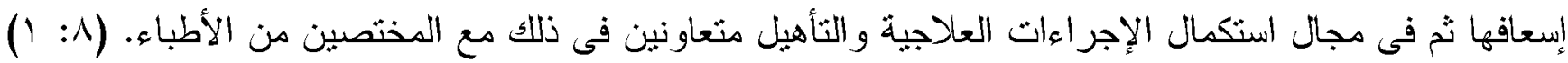

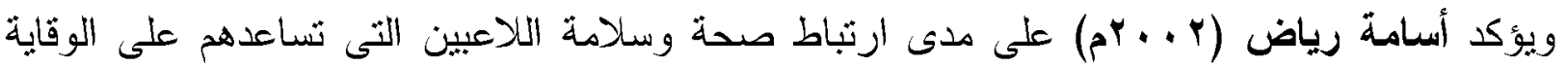
و العلاج كما أنها نعبر عن مدى كفاءة البدن فى مواجهة منطلبات النشاط الرياضى والاهنمام بعناصر اللياقة البدنية للرياضيين مثل القوة، والمرونة والقوة المتفجرة، والرشاقة وهكذا من العناصر التى تعمل على تتمية

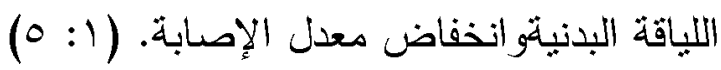

ويؤكدمتصم محمود شطناوى (r + + rم)أن إتقان اللاعب للمهارات الرياضبة، والخبرة تحد من حدوث الإصابة، وبناء عليه فإن الناشئين قد ينعرضون للإصابات الرياضية نتيجة نقص الخبرة لديهم وعدم قدرثهم على الاتقان التام لبعض المهارات الصعبة والتى من المكن أن يتعرض اللاعب للإصابة أثناء التدريب عليها. $(00: 1 \cdot)$

ويشيرمحمد قدرى بكرى وسهام الغمرى نقلا عنبثكيروف (؟19 ام) إلى أن الرياضة الحديثة تتسم بالزيادة الحادة والعالية من حيث الحجم والثدة فى الأحمال التدريية، وهذا بنحنم على جسم الرياضى القيام

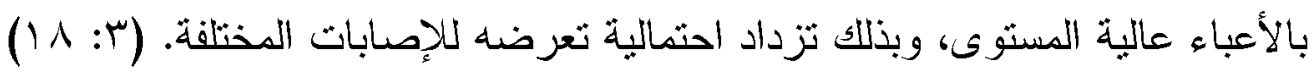

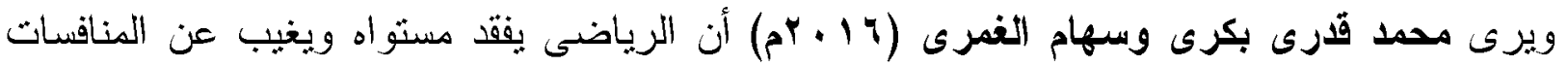
الرياضية بسبب الإصابات الخفيفة ومن الممكن أن تؤدى الإصابات الثديدة إلى الابتعاد عن الممارسة الرياضية.

ويذكر محمد إبراهيم شحاته (910 (م ) ان الثخص الرياضى هو شخص بتميز بالكفاءه واللياقة البدنبة، وله أوضاعه وظروف حياته الخاصة ليحتفظ لنفسه بالجودة والتفوق فى هجال اللعب والحركة، وهو يخصص لهص

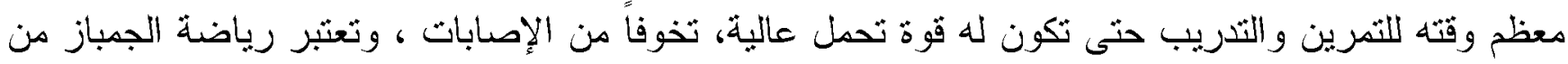

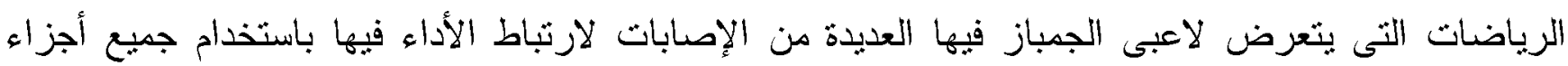

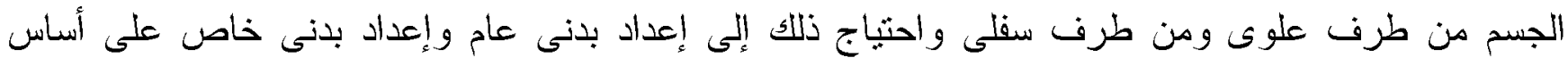

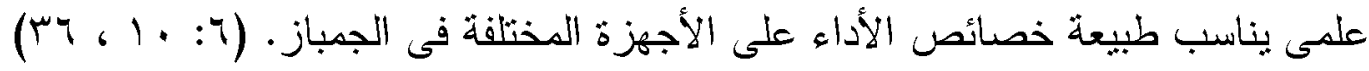

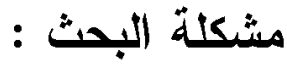

تعثبر الإصابات واحدة من أهم العوامل المؤثرات السلبية على مستوى أداء اللاعيين وخاصة النانشئين حيث تأثر هستوى التقدم والاستمرار بما يحدث في دجال الإصابات الرياضية ومن المشاهدات المنكرره أنها بالرغم من وضع خطط وبر امج لتلاشى هذه الإصابات الرياضية إل أن وضع صعوبات الإت عالية لضمان الحصول

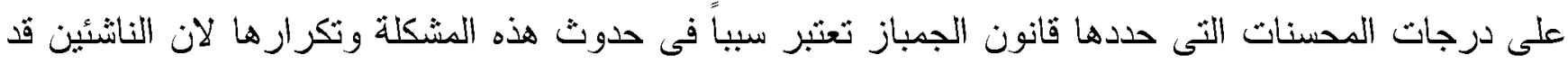


يكون ثم إعدادهم بقدر غير كافى فى الاعداد البدنى العام والخاص لمواجهه المنطلبات الفنبة العالية وتحقيق

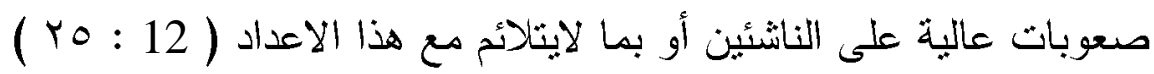
إن الرياضى فى العصر الحديث هو شخص ينميز بالكفاءه واللياقة البدنية وله أوضاعه وظروف حياته الخاصة لبحتفظ لنفسه بالجوده والتفوق في مجال اللعب والحركة وهو يخصص معظم وقته للتمرين والتنريب حثى نكون له قوة تحمل عالية تخوفاً من الإصابات وفى حالة إصابثه فان سهولة إعادة بناء جسمه سنكون ممكنه

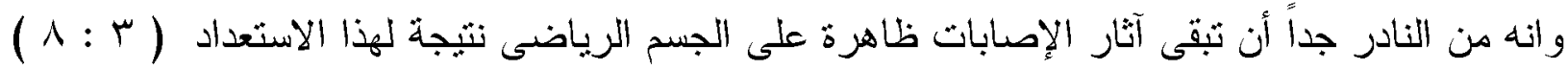

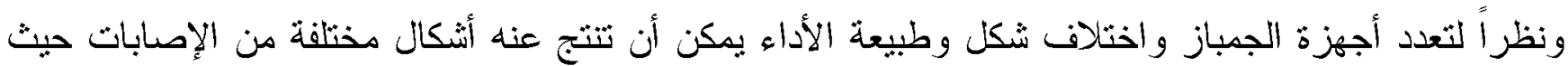

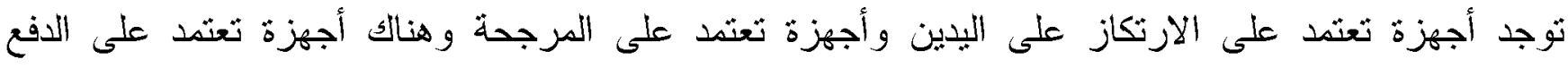

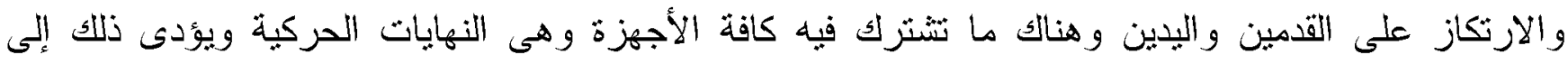
إمكانية اختلات شكل ونوع هذه الإصابات، حيث بعتبر جهاز عش الغراب هو أكثر أجهزة الجمباز تدريبياً

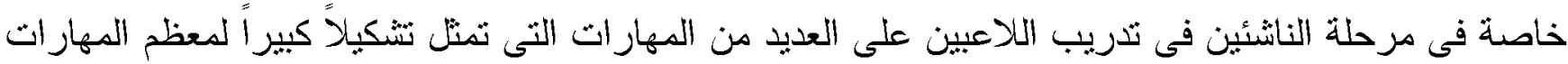
التى تؤدى على العدبد من أجهزة الجمباز لمهارات التى تمثل عنصر أساسى لهذه الأجهزة ونظراً لكثرة التكرارات فى التدريب لهذه المهارات على جهاز عش الغراب ونتيجة للإصابات عليه أن يكون هناك علاقة بين

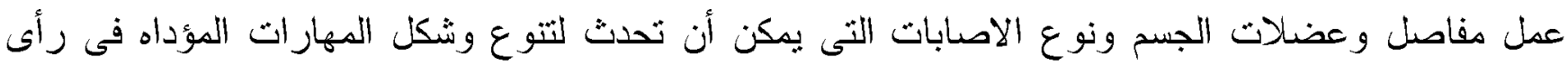
الباحث لدر اسة عنوان البحث "علاقة نوعية الإصابة بخصائص الأداء على جهاز عش الغراب برياضة الجمباز". $(r \cdot: 11)$ هدف البحث: يهذف البحث إلى: التعرف على علاقة نوعية الإصابة بخصائص الأداء على جهاز عش الغراب برياضة

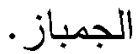

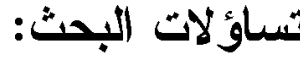

1- ما هى أكثر أنواع الإصابات شيوعاً على جهاز عش الغراب للناشئين للمراحل العمرية V، د، 9 سنوات؟ r- ما هى طبيعة العلاقة بين نوعية الإصابة وخصائص الأداء على جهاز عش الغراب للنانشئين المصطلحات المستخدمة في البحث: الماته

الإصابة "Injury": هى تلف أو إعاقة سواء كان هذا التلف مصاحباً أو غير مصاحباً بنهنك الأنسجة نتيجة

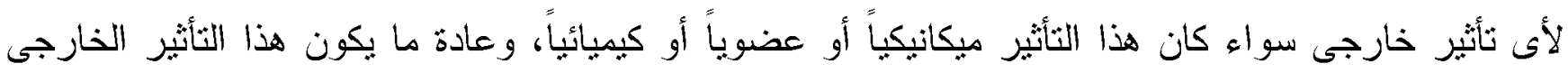

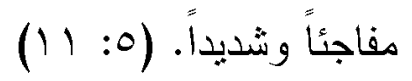
خصائص الأداء على أجهزة الجمباز (*): هى المجموعات الحركية للجمل التى تؤدى على كل جهاز من أجهزة

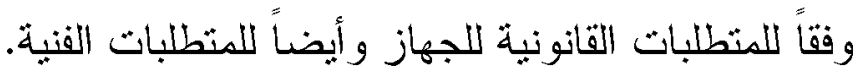


التقلص العضلى Spasm - cramp: هو انقبضات عضلية مؤلمة غير إرادية بالعضلات بسبب عبوب الجهاز العصبى، ويحدث تغيير ات كيميائية فى خلايا العضلات المشتركة فى التمرينات. (0: 7 (1)

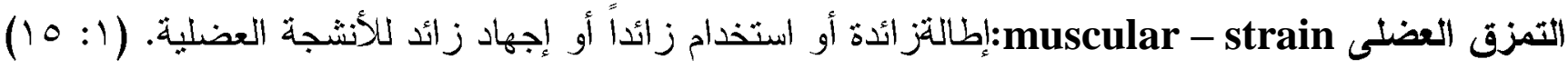

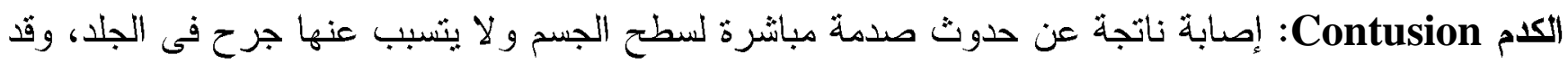
بنتج عنها تجمع دموى. (IV:I) الالتواء Sprain: نطويل أو ضغط مثزايد على الأنسجة الرخوة أو المحفظة الز لالية للمفصل أو الأربطة أو

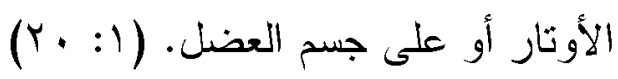
الخلع dislocation: خروج أحد أطراف العظام المكونة للمفصل من مكانها الطيبحى وقد يصاحب هذا نمزق الأربطة، الأنسجة، العضلات المحيطة بالمفصل. (1: (Y) الكسر fracture: إنفسال العظمة جزئياً عن بعضها عن بعض إلى جزئين أو أكثر بسبب قوة خارجية عنيفة. $(r Y: 1)$ مستوى الأداء المهارى("): هى الارجة التى يحصل عليها اللاعب على الجهاز فى ضوء الأداء المهارى للجملة الحركية لواقع الإجباريات القانونية المقررة من قبل اللجنة الفنية للاتحاد المصرى للجمباز . جهاز عش الغراب: أداة المهارات بشكل الازتقاء بقدم واحد أو بالقدمين والارتكاز بيد واحدة أو بكللنا البدين. (rr: $: 11)$

الار اسات السابقة العربية : العابة

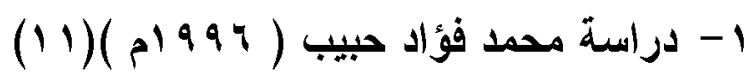

قام محمد فؤاد حيبب ( كو 1999 م ) بإجر اء دراسة بعنوان " الإصابات الثشائعة بين ناثشئى الجمباز" وثهدف

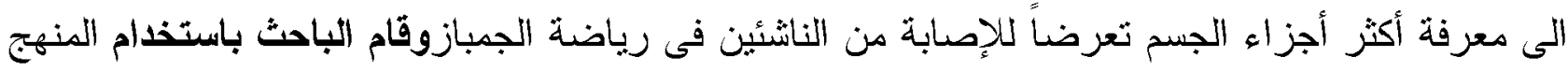
المسحى وكانت العينة ( 0 ؛ ) لاعبا من الناثئين في رياضة الجمباز وكانت الأدوات المستخدمة استماره

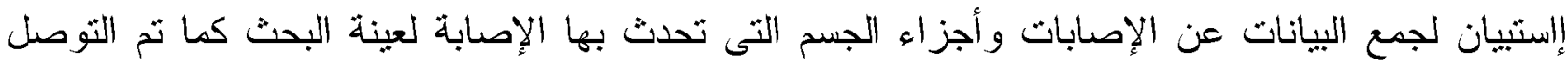

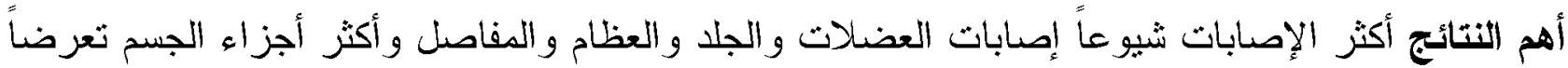

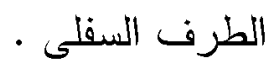

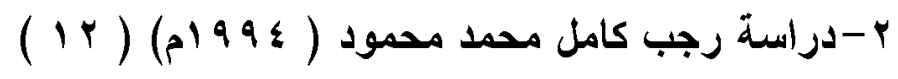

ثام رجب كامل محمد محمود (ـ99 199) دراسة بعنوان دراسة تحلبلية لبعض الإصابات الثنائعة للاعبي

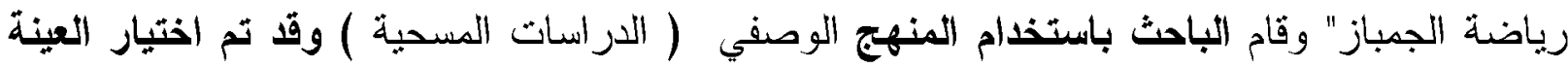

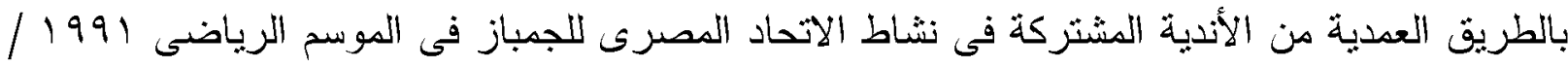

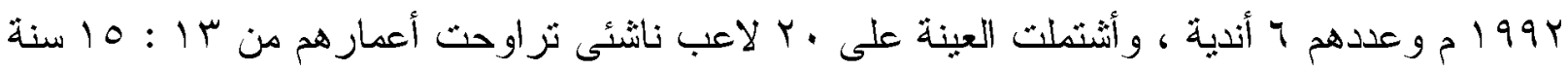

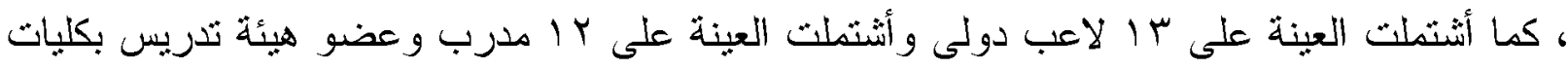


التربية الرياضية قائمين على تدريب رياضة الجمباز في اندية للاتحاد المصري للجمباز واعتمد الدراسة

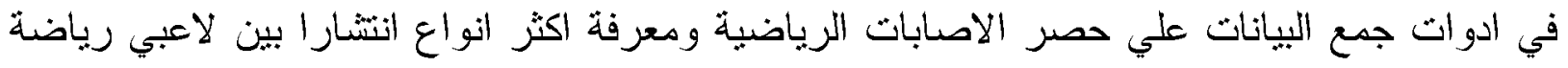

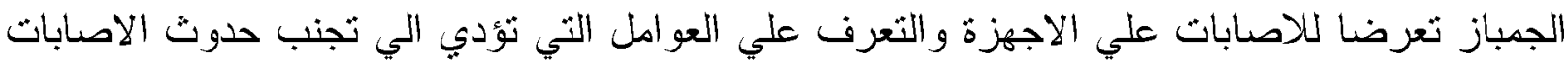

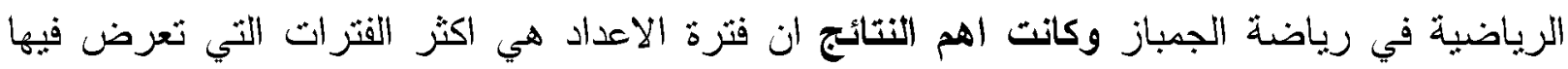

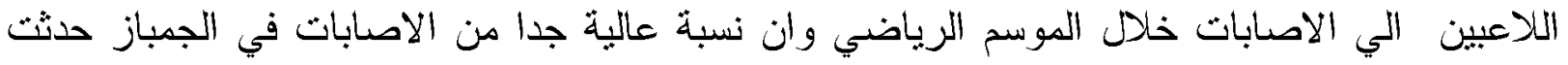

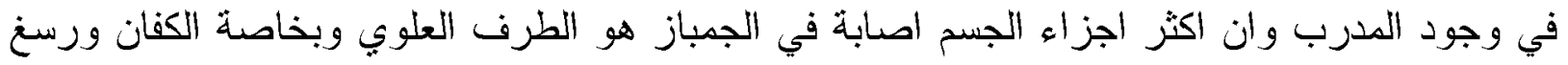
اليد والكتفان وان اكثر انواع الإصابات حدوثا في العظام والعضلات وهي كدمات في الدفاصل الالتواء في الأربطة والتمزقات وهذا أكثر اجهزة رياضة الجمباز التي بتعرض عليها اللاعبون للإصابة

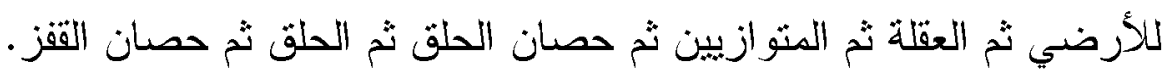

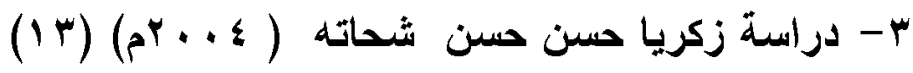

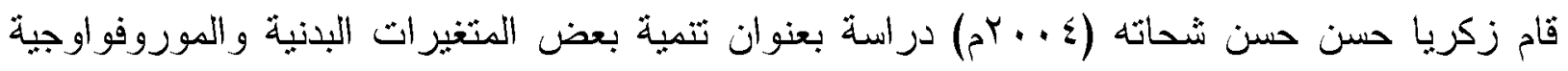
وعلافتها بحدوث الاصابات الرياضية لنانشئ الجمباز وقد استخدم الباحث المنهج التجريبي بطريقة القياس القبلي والبعدي للمجموعتن احداهما تجريبية والاخري ضابطة وقد ثم اختيار العينة بالطريقة

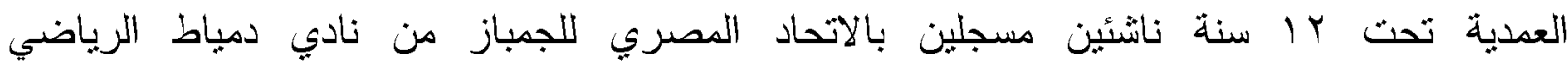

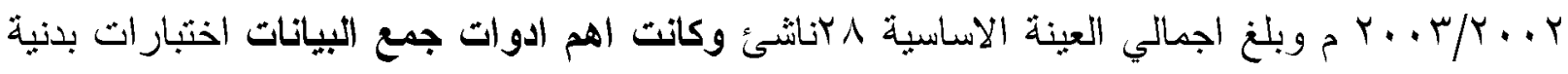
وقياسات موروفولوجية انتتملت علي قياس الدحيطات والاعراض وسمك الدهن وحصر لاهم اماكن الاصابات وانواعها لمقارنة موسمين رياضيين في المتغيرات وكانت نتائجها علي النحو التالي ان اكثر

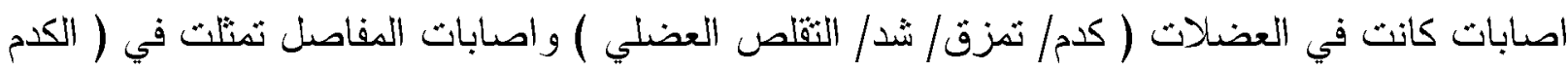

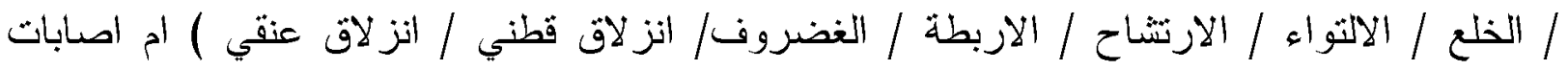
العظام فكانت هي ( كدم / كسر كلي ) ومن خلا نتائج البحث تساهدت التنمية للهنغيرات البدنية و الموروفولوجية في ثقليل والوقاية من الاصمابات عن الموسم السابق مما يدل علي اهمية الاهنمام بهذه

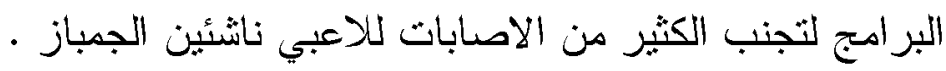

الار اسات السابقة الاجنبية :- البرية

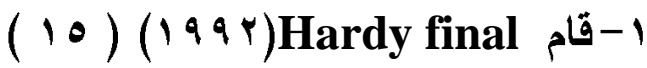

باجراء دراسة بعنوان " الاصدابات الفريق الكندي لجمباز الرجال" وتهدف هذه الدراسة الي التعرف علي

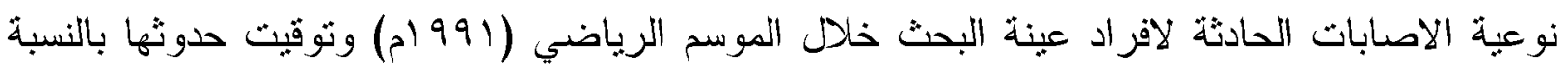
للموسم الرياضي وظروف حدوثها وقام الباحث باسنخدام المنهج الوصفي وكانت العينة 10 لاعب دولي الإني و الأي يثم اختبار اعضاء الفريق القومي الكندي لجمباز رجال منهم وكانت الادوات المستخدمة اسنمارة 
حصر بيانات كما تم التوصل الي اهم النتائج ان القدمين والركبة اكثر اجزاء الجسم عرضه للاصـابات وان اصابات الطرف السفلي اكثر من اصابات الطرن العلوي

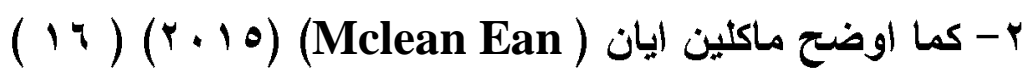
وقد اوضحت دراسة ماكلين ابان ان الاعداد البدني لتمرينات المقاومة للطرف العلوي وخاصة مفصل

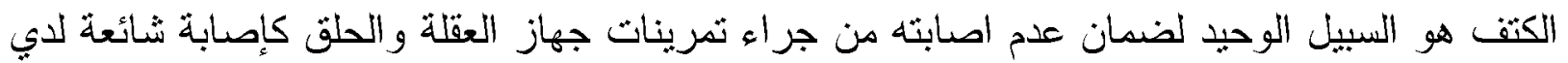

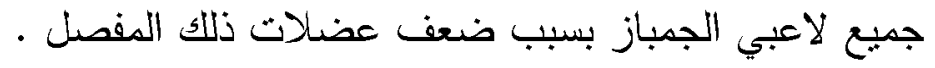

$$
\text { منهرج البحث: }
$$

استخدم الباحث المنهج الوصفى المسحى نظر أ لملاءمثه لطبيعة هذه الدراسة.

$$
\text { عينة البحث: }
$$

اختيرت عينة البحث من الناشُئين فى المرحلة العمرية من V-9 سنوات على ثلاث مراحل ناشئين تحت

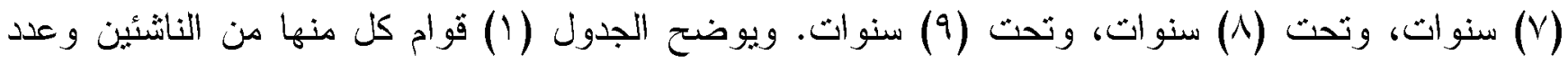

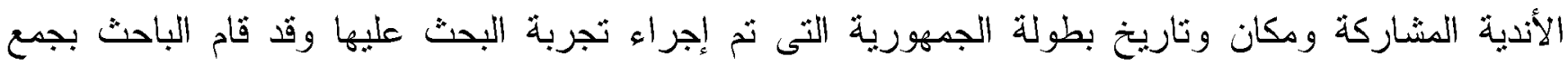

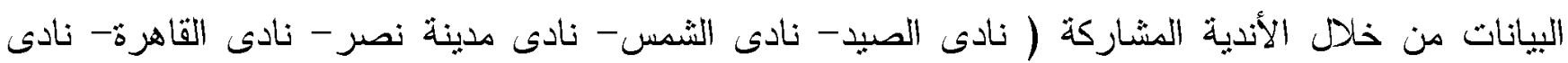

$$
\text { الرواد- نادى الاهلى - نادى وادى دجله ) ). }
$$

\begin{tabular}{|c|c|c|c|c|c|c|c|c|c|}
\hline \multicolumn{3}{|c|}{ ناشنئين تحت (9) سنوات } & \multicolumn{3}{|c|}{ ناشئين تحت (^) سنوات } & \multicolumn{3}{|c|}{ ناشئين تحت (V) سنوات } & \multirow{2}{*}{ المر احل } \\
\hline عدد الأجهزة & عدالأدبية & الناشئين & الأجهزة & الأندية & الناشئين & | عدد & عدالأددية & الناشئين & \\
\hline 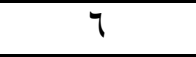 & 7 & & 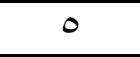 & V & . & $\pi$ & $\Lambda$ & -1 & \\
\hline \multicolumn{3}{|c|}{ 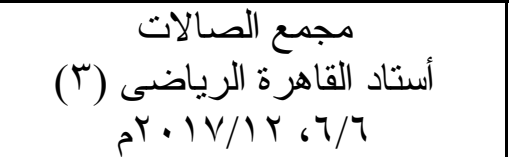 } & \multicolumn{3}{|c|}{ أستاد القاهرة الرياضـى (r) الصاتل } & \multicolumn{3}{|c|}{ 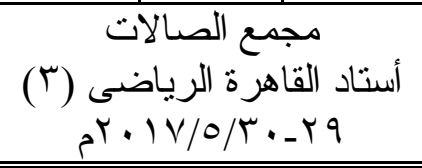 } & كالبن وتاريخ \\
\hline
\end{tabular}

جدول (1)

توصيف مجتمع البحث

شروط العينة: - م

- التسجيل بالنادى و المنطقة الثابع لها الاتحاد المصرى.

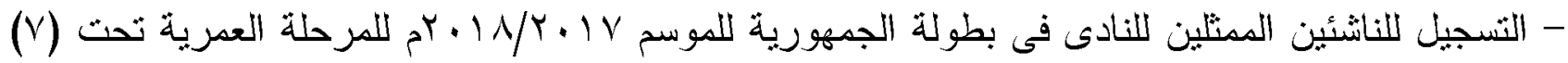

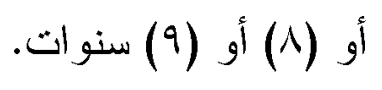


جدول (ץ)

توصبف عينة البحث

\begin{tabular}{|c|c|c|c|c|c|}
\hline الآحر اف المعيارى & |المتوسط الحسابى & وحد القياس & المتغير ات & 5 & المرحلة \\
\hline$\cdot, r \varepsilon$ & $7, Y 1$ & سنة & السن & 1 & الناشئين تحت \\
\hline$\cdot, Y Y$ & $0, Y_{1}$ & سنة & العمر التدريبى & $r$ & سنوات (V) \\
\hline$\cdot, 17$ & $V, Y V$ & سنة & السن & 1 & الناشئين تحت \\
\hline$\cdot, I V$ & r, ro & سنة & العمر التذريبى & T & (^) سنوات \\
\hline$\cdot, 17$ & $\Lambda, r \varepsilon$ & سنة & السن & 1 & الناشنئين تحت \\
\hline$\cdot, 19$ & $\varepsilon, \varepsilon \varepsilon$ & سنة & العمر التذربيى & $r$ & (9) سنوات \\
\hline
\end{tabular}

مجالات البحث:

- المجال البشرى: تم ثطبيق الدراسة على عينة من لاعبى الجمباز من أندية الدرجة الأولى والمسجلين بالاتحاد المصرى لرياضة الجمباز .

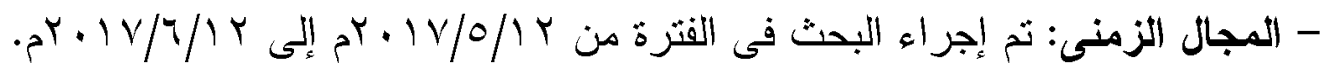

(r) جدول

المجال الزمنى للار اسة

\begin{tabular}{|c|c|c|}
\hline إلى & 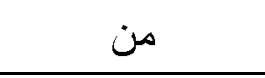 & المجال الزمنى \\
\hline 更 & $a^{r} \cdot 1 V / 0 / 1 r$ & استطلاع آر اء الخبراء \\
\hline$r^{r \cdot \mid V / 0 / Y 1}$ & مr.1V/0/r. & التجربة الاستطلاعبة \\
\hline${ }^{r} \cdot 1 V / Y / 1 r$ & pr. IV/0/rq & تطييق الاستثارة \\
\hline
\end{tabular}

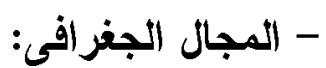

ثم تطبيق الدراسة على الأندية المصرية المشاركة فى بطولات الجمهورية للناشئين تحث (V)، (入)، (9)

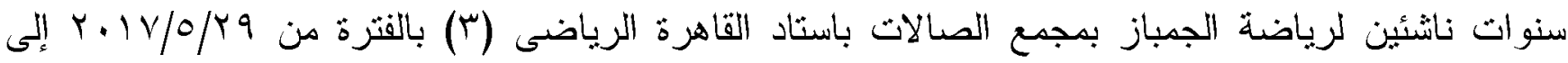

$$
\begin{aligned}
& . r^{r} \cdot 1 \mathrm{~V} / \mathrm{Y} / \mathrm{T} \\
& \text { أدوات جمع البيانات: }
\end{aligned}
$$

قام الباحث بمفرده بجمع البيانات أثتاء كل بطولة فى المراحل العمرية (V)، (A)، (9) سنوات لحصر الاصابات قيد البحث:

- اسثمارة جمع بيانات للإصـابات التى تحدث أثتاء كل بطولة في المر احل العمرية (V)، (入)، (9) سنوات. - المقابلة الثخصبية. - سجلات نتائج كل بطولة جمهورية لكل مرحلة عمرية من الناشئين (V)، (^)، (9) سنوات. - استمارة الخبير، نموذج من استمارة تفريغ بياناث الإصابات الثى تحدث أثناء كل مرحلة من المراحل العمرية . 
- وفى ضوء ما أبداه الخبر اء من ملاحظات ثام الباحث بإجر اء التعديلات وضع استمارة جمع البيانات للاجابات

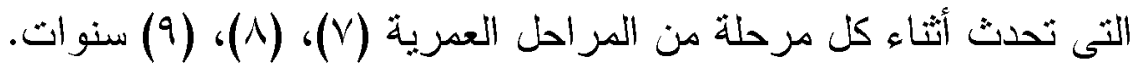

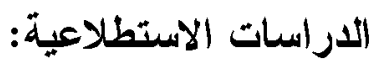

ثام الباحث بمقابله شخصية للمدرب واللاعبين وهى مرحلة التجريب الميدانى لرصد نوع الإصابة

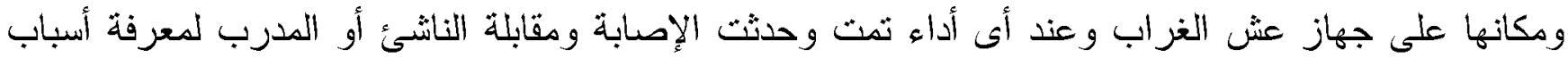
الإصدابة.

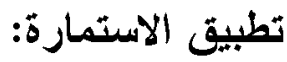

ثم تطبيق الاسنمارة على كافة اصابات النانشئين التى حدثت خلال البطولة وتفريغ البيانات في جداول لكل مرحلة وتحديد اسم اللاعب والجهاز موضحاً نوع الإصابة لنحديد أكثر الإصابات شيوعاً على جهاز فى كل

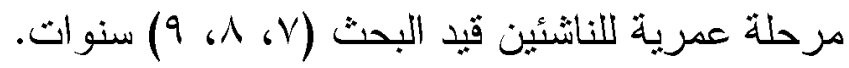

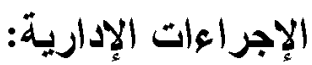

تم الحصول على خطاب موجه من كلية التربية الرياضية للبنين - جامعة الزقازيق إلى مدير الاتحاد المصرى للجمباز بمجع الاتحادات الرياضية واللجنة الأولمبية المصرية باستاد القاهرة الدولى بمدينة نصرية الرئه

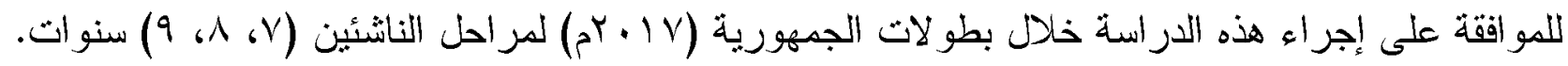
تطبيق الار اسدة:

تم تطييق الدراسة بالمنهج الوصفى بالدراسة المسحية على بطو لات الجمهورية للمراحل الثلاثة للناشئين

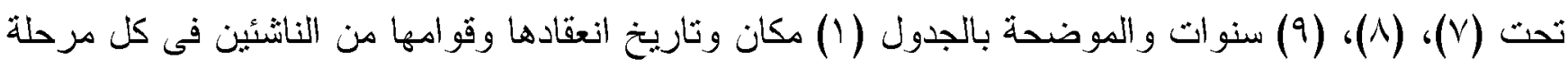

و وعد الآندية المثناركة فى كل مرحلة عمرية. المعالجة الإحصائية:

استخدم الباحث المعالجات الإحصائية التالية:

$$
\begin{aligned}
& \text { - عدد مرات التكرار لكل إصـابة. } \\
& \text { - النسبة المئوية \% }
\end{aligned}
$$

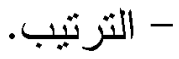

$$
\begin{aligned}
& \text { - المتوسط الحسابى } \\
& \text { عرض ومناقثة النتائج: } \\
& \text { عرض التتانُج: } \\
& \text { التساؤل الأول: }
\end{aligned}
$$

"ما هى أكثر أنواع الإصابات شيو عاً على جهاز عش الغراب للناشُئين V، د، 9 سنوات؟". 


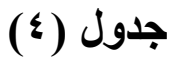

الأهمية النسبية لتحديد أكثر نوع الإصابات على جهاز عش الغراب لمرحلة تحت V سنوات (ن = 1 اه ناشئ)

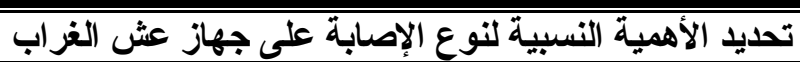

\begin{tabular}{|c|c|c|c|c|}
\hline الترتيب & النسبة \% & تكرارات & & نوع الإن \\
\hline . & . & - & كلمات عضلات & $T$ \\
\hline$\cdot$ & . & • & كلمات عظام & $\bar{r}$ \\
\hline . & $\% 1, \cdot \varepsilon$ & 1 & كلمات مفاصل & $\bar{r}$ \\
\hline • & . & • & ش شضد عضلى & \{ \\
\hline . & $\% 1, \cdot \varepsilon$ & 1 & تقلص عضلي & 0 \\
\hline . & $\cdot$ & - & تمزق عضلي & 7 \\
\hline . & . & . & إلتواء & $\bar{v}$ \\
\hline$\cdot$ & $\% 1, \cdot \varepsilon$ & $T$ & خلع & $\bar{\Lambda}$ \\
\hline . & . & . & كسور & 9 \\
\hline - & $\% \Gamma .1 Y$ & $r$ & \multicolumn{2}{|c|}{ المجموع } \\
\hline . & . & . & \multicolumn{2}{|c|}{ النسبة المئوية (\%) } \\
\hline$\cdot$ & . & الثانى & \multicolumn{2}{|l|}{ الترتيب } \\
\hline
\end{tabular}

يوضح الجدول السابق رقم (ء) تحديد نوع الإصابات التى نم حدوثها فى بطولة الجمهوربة لناشىى

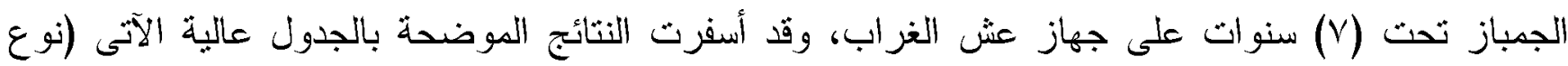
(الإصابة):

كدمت مفاصل حالة واحدة بنسبة مئوية للمشاركين ؟ ., ا \%.

تقلص عضلى حالة واحدة بنسبة مئوية للمشاركة ؟ ., 1\%.

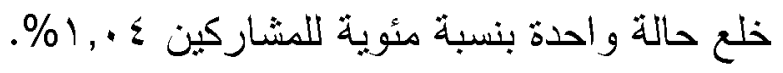

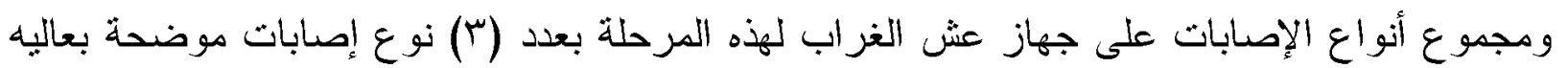

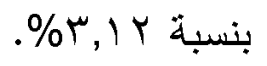

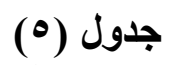

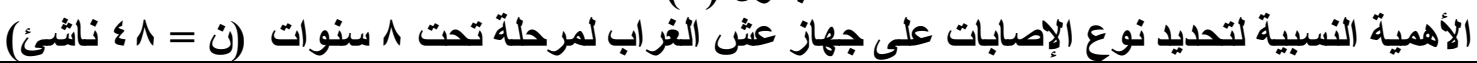
الألهمية النسبية" تكرارات

\begin{tabular}{|c|c|c|c|c|}
\hline . & . & . & كدمات عضلات & 1 \\
\hline . & . & . & كدمات عظام & 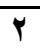 \\
\hline . & • & . & كلمات مفاصل & $r$ \\
\hline . & . & . & ش شضلى عضل & $\varepsilon$ \\
\hline . & $\% 1,19$ & 1 & تقلص عضلى & 0 \\
\hline . & $\cdot$ & . & تمزق عضلى & 7 \\
\hline . & $\% 1,19$ & $T$ & 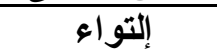 & $\bar{v}$ \\
\hline$\cdot$ & . & . & خلع & $\Lambda$ \\
\hline$\cdot$ & • & . & كسور & 9 \\
\hline الثالث م & $\% \curlyvee, \Gamma \wedge$ & r & \multicolumn{2}{|c|}{ المجموع } \\
\hline . & . & . & \multicolumn{2}{|c|}{ النسبة المئوية (\%) } \\
\hline . & . & الثالث م & \multicolumn{2}{|c|}{ الترتيب } \\
\hline
\end{tabular}


يوضح الجدول السابق رقم (0) تحديد نوع الإصابات التى ثم وقوعها فى بطولة الجمهورية لنانشئى

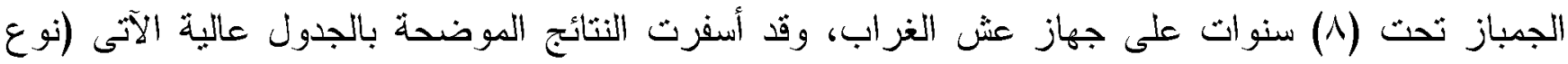

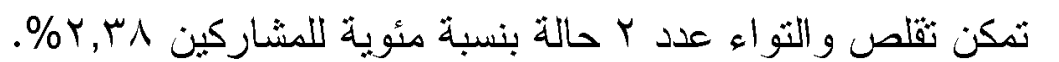
ومجموع أنو اع الإصابات على عش الغراء اعلى لهذه المرحلة بعدد (Y).

وجاء نزتيب جهاز عش الغراب فى عدد الإصابات (الترتيب الثالث م) فى هذه المرحلة فى إجمالى نوع الإصابات الرياضية على الأجهزة الخمسة المقرة على مرحلة تحت 1 سنوات ناتشئين.

جدول (7)

الأهمية النسبية لتحديد نوع الإصابات على جهاز عش الغراب لمرحلة ناثنئن تحت 9 سنوات

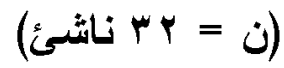

\begin{tabular}{|c|c|c|c|c|}
\hline \multicolumn{3}{|c|}{ تحديد الأهمية النسبية لنوع الإصابة على جهاز عش الغراب } & \multirow{2}{*}{\multicolumn{2}{|c|}{ نوع الإصابة }} \\
\hline الترتيب & النسبة \% & تكرارات & & \\
\hline$\cdot$ & • & • & كلمات عضلات & 1 \\
\hline . & . & . & كلدمات عظام & $r$ \\
\hline$\cdot$ & $\cdot$ & $\cdot$ & كلمات مفاصل & $r$ \\
\hline الأول & $\%^{0}, \wedge \wedge$ & $\varepsilon$ & شد عضلى & $\varepsilon$ \\
\hline$\cdot$ & $\cdot$ & $\cdot$ & تقلص عضلى & 0 \\
\hline - & . & . & تمزق عضلى & 7 \\
\hline$\cdot$ & $\cdot$ & $\cdot$ & إلتو اء & V \\
\hline الثانى الثي & $\% \leqslant, \leqslant 1$ & $r$ & خلع & $\Lambda$ \\
\hline . & . & . & كسور & 9 \\
\hline الأول & $\% 1 \cdot, r^{q}$ & $\mathrm{~V}$ & \multicolumn{2}{|c|}{ المجموع } \\
\hline - & - & - & \multirow{2}{*}{\multicolumn{2}{|c|}{ النسبة المئوية (\%) }} \\
\hline$\cdot$ & - & الأول & & \\
\hline
\end{tabular}

يوضح الجدول السابق رقم (T) تحديد نوع الإصابات النى نم وقوعها في بطولة الجمهورية لناشئى الجمباز تحت (9) سنوات على جهاز عش الغزاب، وقد أسفرت النتائج الموضحة بالجدول عاليه الآتى (نوع

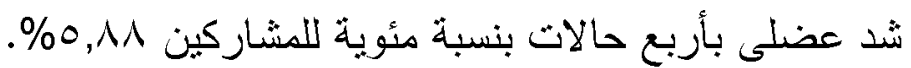

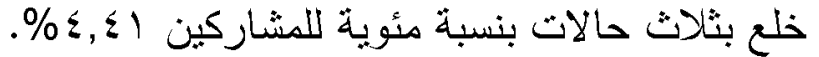

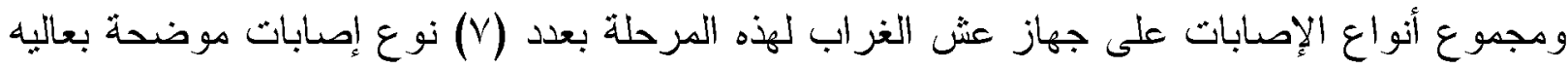

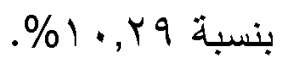
وجاء نرثيب جهاز عش الغزاب فى عدد الإصابات (الثرنيب الأول) فى هذه المرحلة فى إجمالى نوع الإصـابات الرياضية على الأجهزة الستة المقررة على مرحلة تحت 9 سنوات ناتشئين. 
توجد علاقة ارتباطية بين نوعية الإصابة وخصائص الأداء على جهازعش الغراب فى كل مرحلة

- أن قيمة كاب المحسوبة أقل من قيمة كاب الجدولية مما يؤدى إلى عدم وجود دلالة إحصائبة ارنباطية.

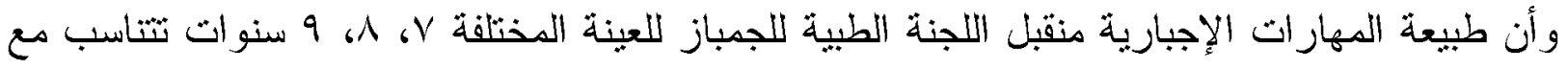
طبيعة الجمل الحركية الإجبارية للمصابين للاعبين من خلال اللجنة الفنية للجمباز، يؤكد تتاسبها للمراحل المختلفة من حيث جهد العمل العضلى لهذه المراحل، ويظهر ذلك كاب فى جميع المراحل العمرية V، ه، 9 سنوات، وطييعة الأداء على جهاز عش الغراب على عدم وجود علاقة إحصائية ارثباطية.

مناقشة النتائجج:

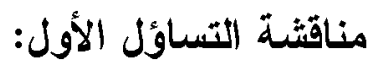
"ما هى أكثر أنواع الإصابات شيول عاً على أجهزة الجمباز للنانشئين V، د، 9 سنوات؟".

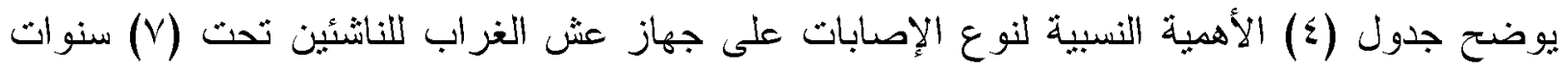

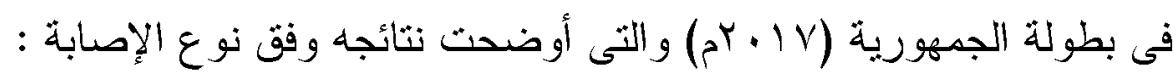

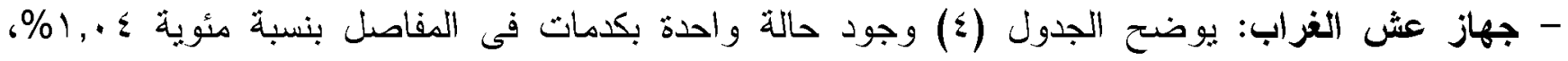

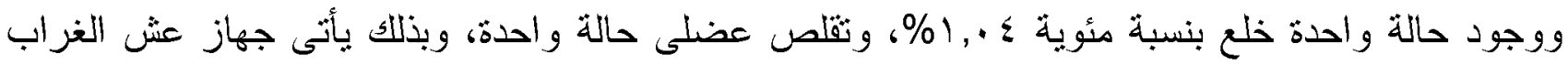

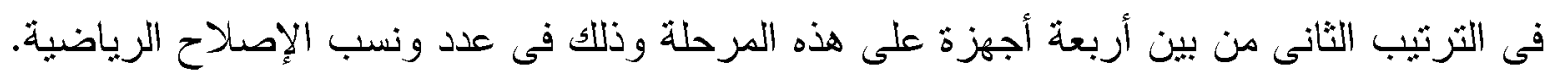

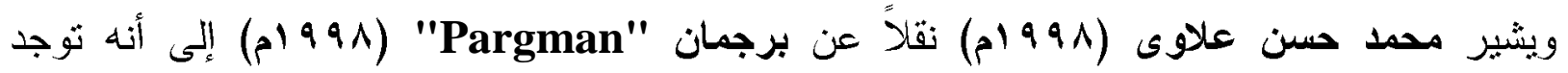
إحصائيات رياضية تثير إلى أن هناك (V) لاعبين من بين كل (• () لاعبين بعانون الإصابات البدنية الرياضية المختلفة طو ال فترة حياتهم وبذلك ينقطعون عن التنريب والاثشتراك فى المنافسات الرياضية لفترة طويلة تشراوح

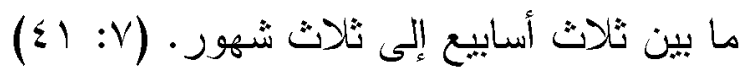

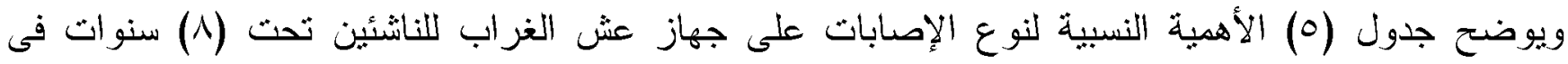

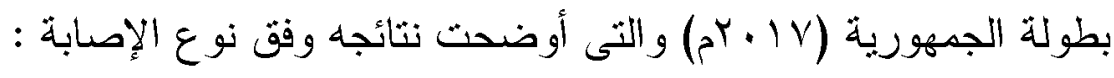

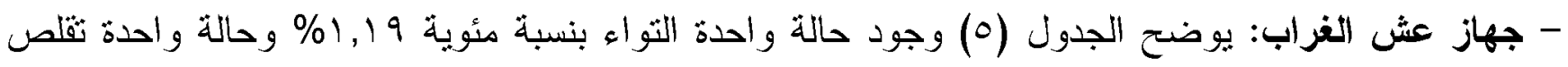

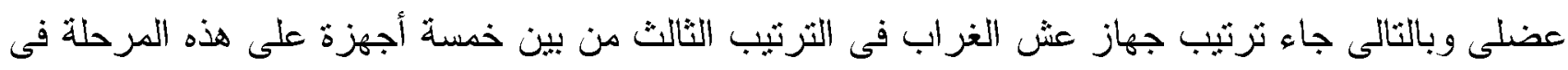
عدد نسبة الإصدابات الرياضية. ويوضح جدول (آ) التكرارات و النسب المئوية والترتيب لنوعية الإصابات على أجهزة الجمباز للنانشئين

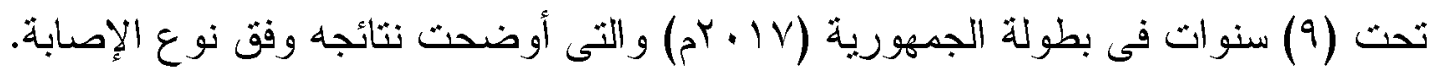




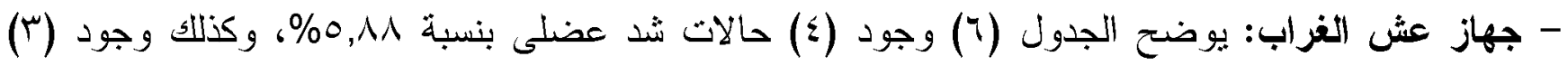

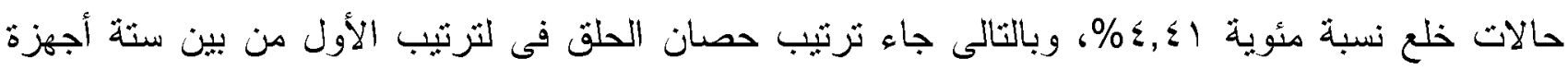

$$
\text { - على هذه المرحلة فى عدد ونسبة الإصابات. }
$$

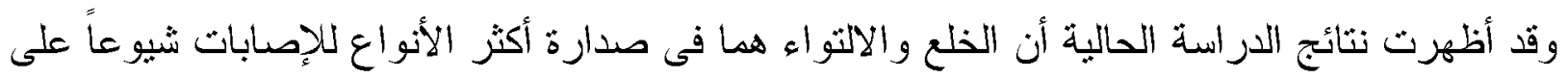

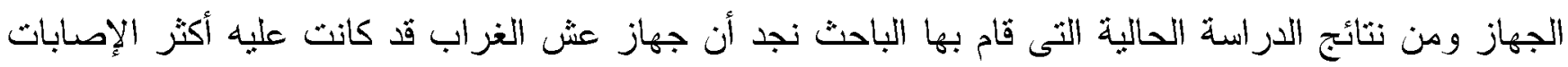

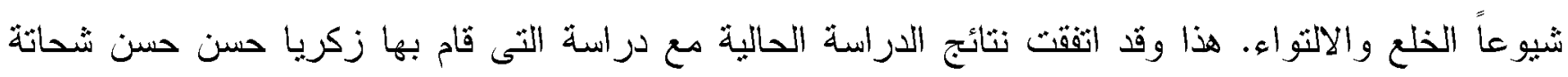

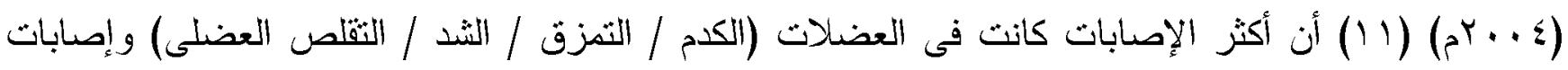

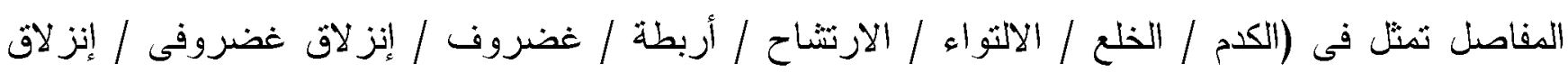
عنقى) أما إصابات العظام كانت (كدم / كسر كلى). ونوضح الدراسة الحالية أن الكفين هما نقطة الارتكاز واتصال اللاعب بجهاز عش الغراب و المسئولين عن القبض على الجهاز وعند الانتقال على أجزاء جهاز عش الغراب قد بخطئ اللاعب فى اختئ اختيار المكان

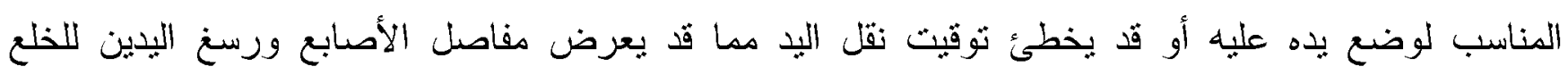
والالتو اء أو الرضوض وضع والكدمات.

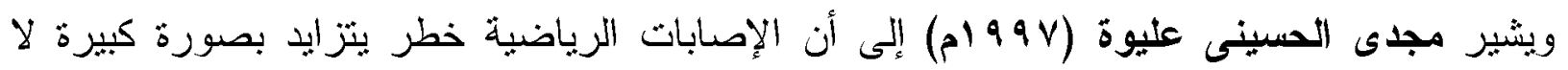
تقتصر فقط على متحدى الدستويات العالية فى الرياضة والذين يتدربون لتسجيل أرقام جديدة وقياسية أو الأداء

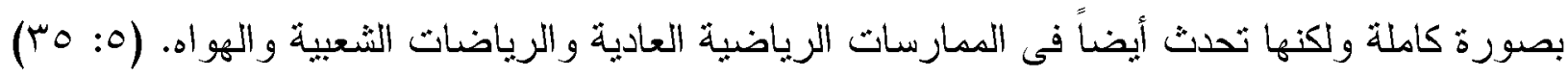
وتوضح الدراسة الحالية أيضاً إلى إن الاتقان لمهارة الثلويح الجانبة على حلقتى عش الغراب وتحقيق مسار

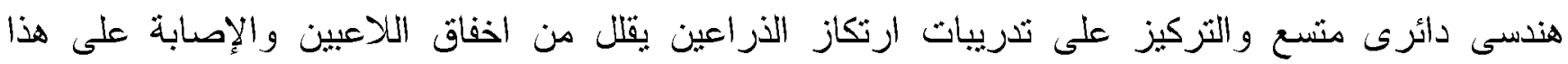
الجهاز - الجناز

- أكثر أنو اع الإصابات شيو عاً فى مرحلة نانشئين تحت (V) سنو ات:

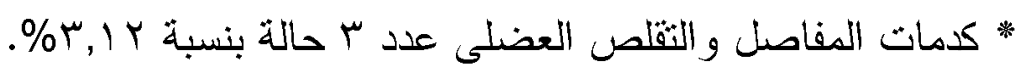

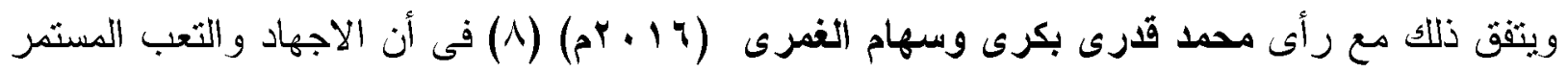

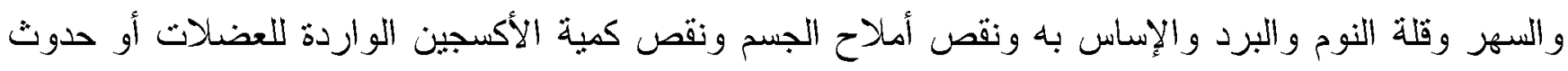

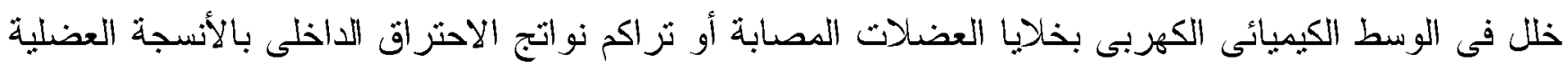

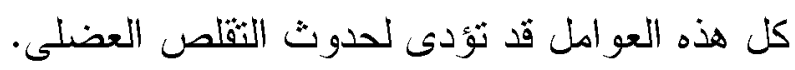

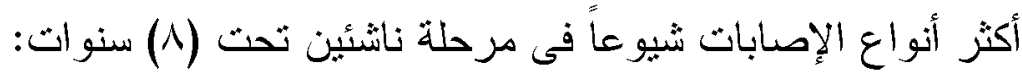

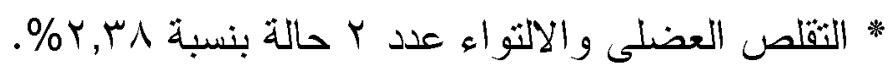
* تقلص العضلات: 
يزى الباحث أن السبب الرئيسى للتمزق العضلى هو عدم تأهيل العضلة للجهد المبذول أو عند حدوث

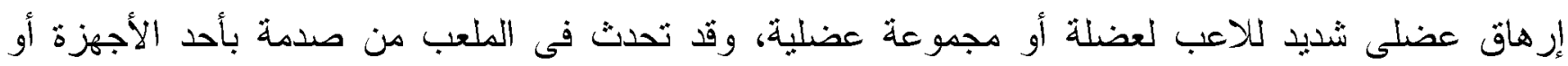

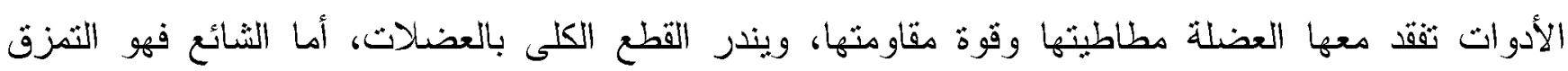

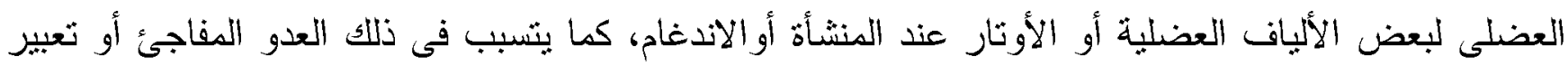

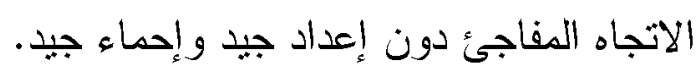

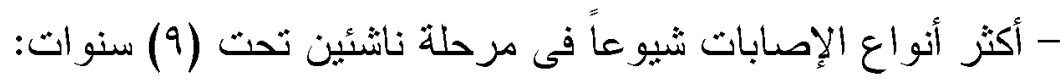
- جهاز عش الغراب بالجمباز الى ثم عليها إصابات لكل مرحلة:

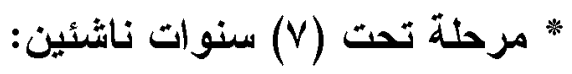

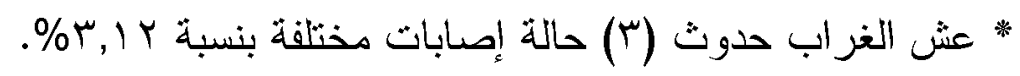

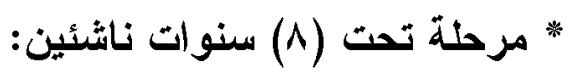

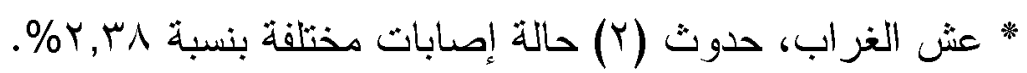

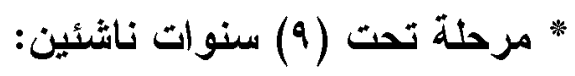

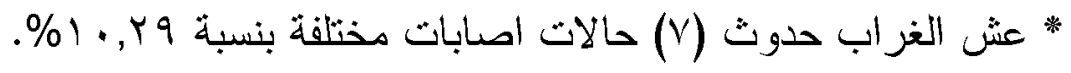

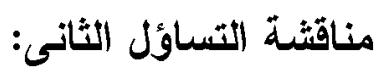

ما هي طبيعة العلاقة بين نوعية الإصـابة وخصائص الأداء على جهاز عش الغراب للناشئين؟ 1- فى ضوء النتائج والدراسات السابقة وجد أن قيمة كاب المحسوبة أقل هن كاب الجدولية للمر احل العمرية المختلفة V، 入، 9 سنوات لا ثوجد علاقة إحصائية ارتباطية وإن طبيعة العمل على الجهاز يحتاج إلى خبرة

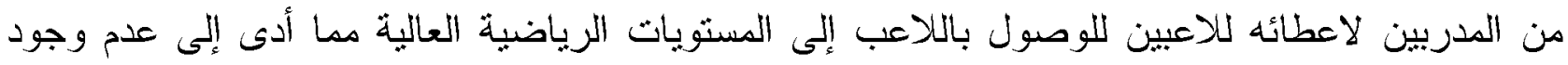
اصابات رياضية كثيرة للمرحلة V، A، 9 سنوات على جهاز عش الغراب بنسبة مئوية عالية نظراً لعدم

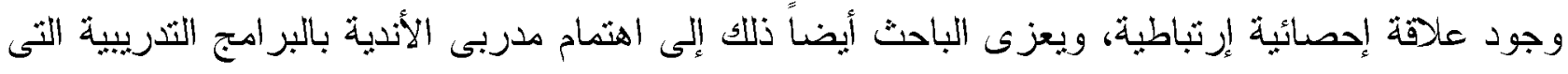
ساعدت على تحقيق حدة الإصابات الرياضية لهذه المر احل حتى ثتاح لهم الفرصة فى مو اصلة التثريب لهذه

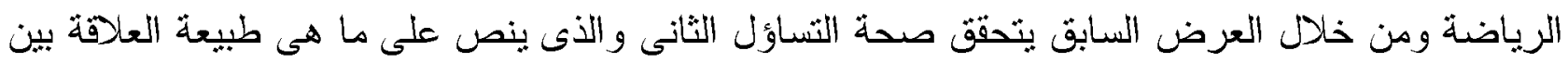
نوعية الإصابة وخصائص الأداء على جهاز عش الغراب للناشئين.

الأستخلاصات و التوصيات:

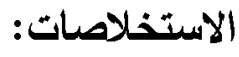

1- أكثر أنواع الإصابات شيو عاً فى مرحلة ناشئين تحت (V) سنوات:

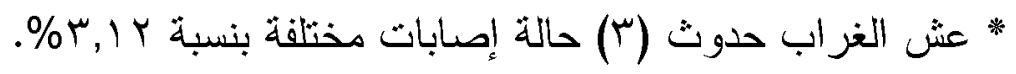

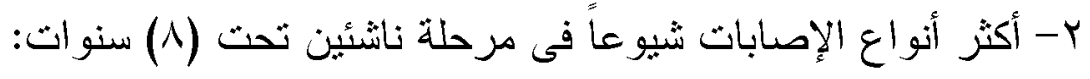

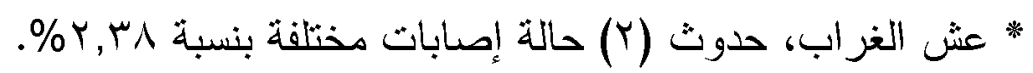




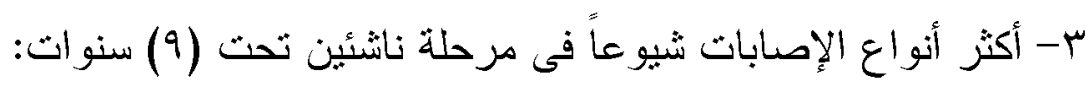

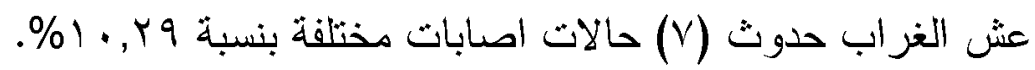

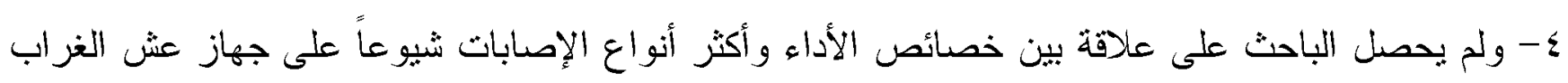

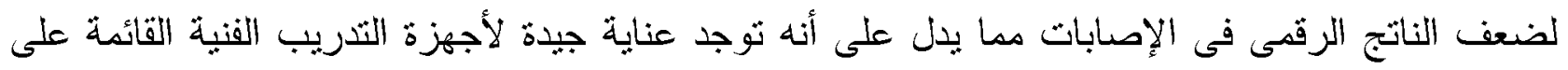
فرق الأندية واهتمامها بالبرامج التدريبية، مع عدم إغفال التتويه بمزيد من ذلك التهات لتلاشى أى اصدابات. التوصيات:

ا- يوصى الباحث بإجراء بحوث للمراحل العمرية المثقدة لإيجاد العلاقة لخصائص الأداء مع نوعية الإصابة على أجهزة الجمباز الفنى للرجال.

r- النوصية لكافة الأجزة الفنية العاملة بالأندية المصرية بالاهنمام بتتفيذ الأحمال التذريبية والاهتمام بفترة الاعداد على جهاز عش الغراب بما يؤدى إلى التأثنير الإيجابى والوقاية من الإصدابات الرياضية. 
1- أسامة رياض (ץ . +rم): الإسعافات الأولية لإصابات الملاعب، الطبعة الأولى، مركز الكتاب للنترر، جامعة حلوان.

r- أسامة رياض (999 (99): الطب الرياضى والعلاج الطييعى، طا، مركز الكتاب للنشر، القاهرة.

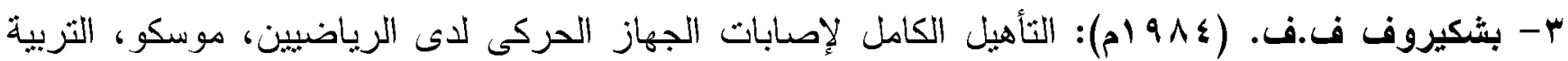

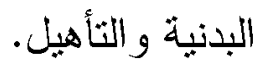

ع- زينب العالم (99 9 (م): التدليل الرياضى وإصابات الملاعب، دار الفكر العربى، طع؛، القاهرة.

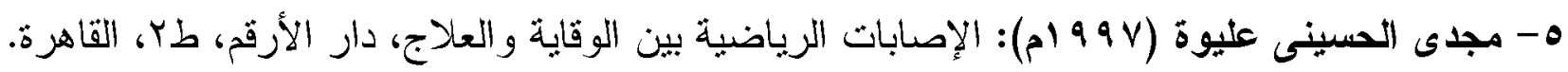

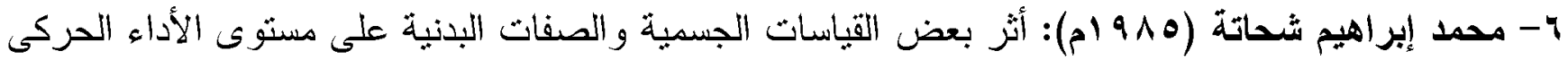

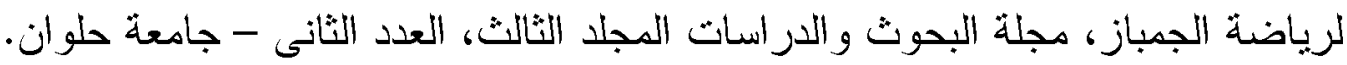

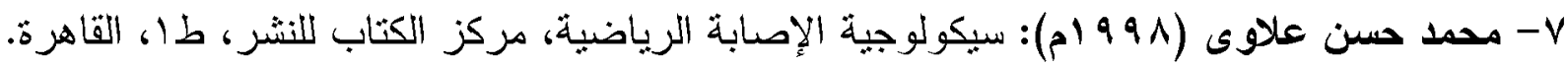

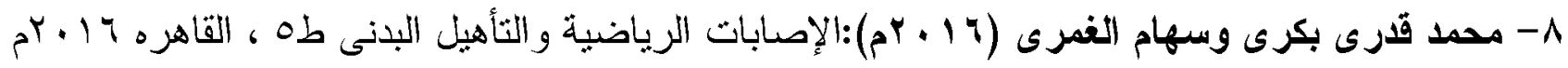

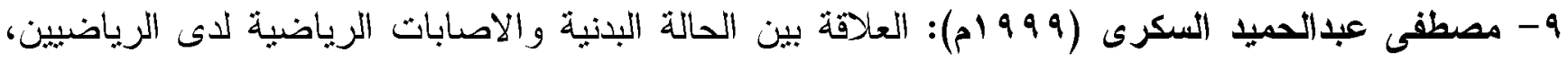
رسالة ماجستير، جامعة حلوان.

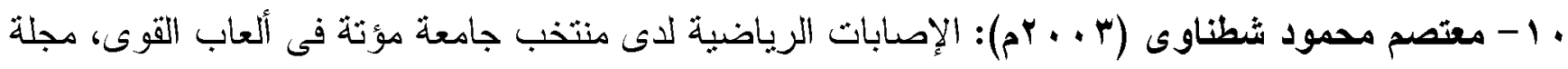

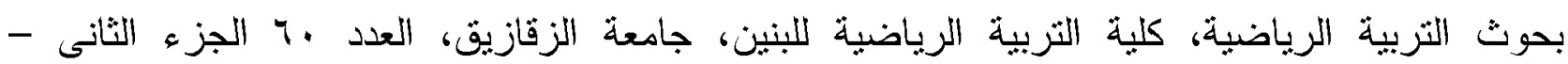
أغسطس.

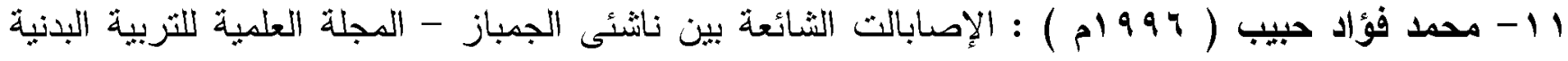

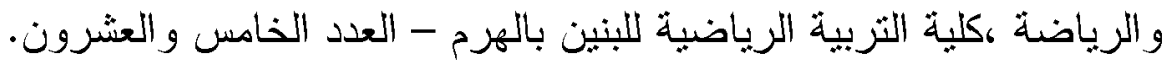

ץ ا- رجب كامل محمد محمود ( ؟99ام ): نحليلية لبعض الإصابات الثائعة للاعبى الجمباز - رسالة ماجستير - كلية التربية الرياضيةزة - جامعة أسيوط.

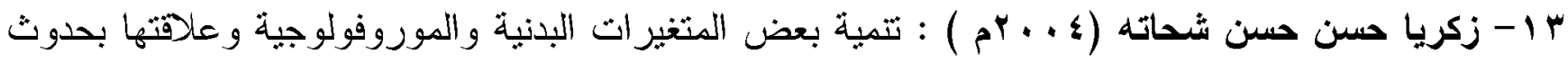

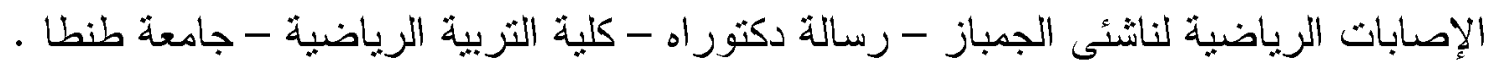
ثانياً: المراجع الأجنبية:

1 \&- International Gymnastic federation (2013): Code of points for men's artistic Gymnastic competitions.

10 -Hardy Final ( 1992 ): injuries and the gymnastics national tear of canbaInternational gymnastic"sndy sports"santamoro. 
17-Mclean Ian ( 2015 ) : injuries among senior officer attending the u.s.a army was college acomedia year .

$$
\text { ثُالثاً: مراجع شبكة المعلومات العالمية (الإتترنت): }
$$

IV- http://www4.infotrieve.com/search/databases/newsearch/asp. 